SHS Web of Conferences 17, 01009 (2015)

DOI: $10.1051 /$ shsconf/ 20151701009

(C) Owned by the authors, published by EDP Sciences, 2015

\title{
Preliminary Studies on Technique Route Design in Forestry Economy
}

\author{
Xinxi Jiang ${ }^{1}$, Wei Zhang ${ }^{2}$, Minwen $\mathrm{He}^{3}$ \\ ${ }^{1}$ Professor of Business School, Jiangxi Normal University, Nanchang, 330022, Jiangxi, China \\ ${ }^{2}$ Postgraduate of School of intercultural studies, Jiangxi Normal University, Nanchang, 330022, \\ Jiangxi, China \\ ${ }^{3}$ Postgraduate of Business School, Jiangxi Normal University, Nanchang, 330022, Jiangxi, China
}

\begin{abstract}
In the process of forestry economical development, the type and effectiveness of technology, choice and use of technology, as well as the developmental power that technological innovation brings about, have made developmental direction and developmental process of the forestry economy diversified. Although the design of technological routes has no simple rule to guide, the associated method and dialectical unification method can be used to intergrate the technology system. This paper exactly proceeds from three angle, which are the core technology, technology group and technological innovation direction, puts forward some choose methods of core technology for technical design route, analyses selection principle of technology group and content of technological innovation, and points out restricting element of technological innovation.
\end{abstract}

Keywords. technique route; core technology; forestry economical; forestry economy

\section{Introduction}

In order to achieve the forestry economic objective of sustainable development, there are two alternative paths: one path is symbiosis with nature; the other path is is to use high-technology.

The system of community succession at the core of ecological cycle in natural basin forms ecological, economic, cultural and social characteristics of the drainage area. The economic behaviors of human beings must adapt to and abide by the laws of the natural ecology to achieve harmony with nature (symbiotic)--This is the first path: the sustainable developmental society of symbiosis with nature. The deficiency of this path is that the growth of natural productivity often lags behind the growth of demands of people's material and spiritual and culture, therefore, people are desirous to supplement the lack of the natural productivity by using innovative technology. The system of industrial clusters succession which is at the core of regional economical development forms characteristics of regional competition in human society. That is to say social change, cultural progress and technological progress are bound to guide (or induce) the formation of regional industry group which are pro-competitive, thus realizing regional development rapidly (sustainable development under the conditions of competition)--This is the second path: the sustainable developmental society of high-tech (including high culture). The deficiency of this path that is the so-called high-tech operational economy would be likely to result in a large number 
of environmental problems and energy issues and makes many natural resources non-renewable, which will be likely to bring the risk of unsustainable development once again.

In the process of forestry economical development, the type and effectiveness of technology, choice and use of technology, as well as the developmental power that technological innovation brings about, have made developmental direction and developmental process of the forestry economy colorfully. Although the design of technological routes has no simple rule to guide, we can be integrated design by associated method and dialectical unification method.

\section{Technique route Design}

\subsection{Selection of the core technology}

There is a key technology that play an important role in any industry (referred to as the core technology), but single core technology can not form a technological system. If the technological system is absent of a (or some) technological link, it will not help the entire technological system to provide complete technological support. So choosing what kind of core technology in industry is a important prerequisite of whether the industry has the development space of technology.

The selection of core technology has a number of ways. First, similar to the basic principles-That is to choose similar framework in the principle of physics, chemistry, biology or engineering. For example, the principle of asexual propagation among the forest tree breeding (method of somatic cell clone, method of grafting, cuttings, etc.), the principle of genetic breeding (hybridization method, transgenic method, genetic recombination, etc.); the principle of artificial regeneration among forest measures (natural seeding method, the method of artificial stump to promote natural regeneration etc.), the principle of artificial improving species competition (pruning, miscellaneous cutting, weeding, irrigation, etc.), the principle of ecological balance (mixed coniferous broad leaved forest, fire prevention forest, biological control of pests and diseases, etc.); Second, intensive operation methods-- to choose at the aspects of effective use of resources and scale business, such as coppice system (dense dwarf fruit trees as early as cultivation, camphor forest taking borneol method, etc.), tree-based intercropping method (herb-shrub-trees model of multiple cropping, agro-forestry, pig-methane-fruit mode, etc.); Third, the market association method--to choose under the conditions that there are a aggregative effects in product, value, region and other aspects, such as essential oils extraction and fractionation (litsea cubeba oil, cedar oil, eucalyptus oil, camphor oil etc.), hot briquetting artificial board technology (flakeboard, veneer, fiberboard, etc.), carbonization technology (bamboo- vinegar and bamboo-charcoal, wood-charcoal and wood-vinegar, activated carbon, bone carbon, shellfish carbon, straw carbon and other biological carbons), fibrosis technology (pulp, textiles, fiber board, carbon fiber, etc.), biotechnology (breeding, product processing, bio-energy, etc), and wood packaging technology (packaging materials of poplar veneer, packaging materials of bamboo, packaging technology of wood machinery pulp, packaging materials of liana, etc); Forth, selection of technological evolution--to choose according to evolutionary(evolutional and developmental) patterns of science and technology, such as the super-activated carbon manufacturing technology (nanometer-fibrous activated carbon, high surface area bamboo (wood) tar activated carbon, high surface area larch bark tar activated carbon, etc.), economic forest transgenic breeding / processing technology (genetically modified production technology of woody fuel, woody transgenic production technology of Chinese herbal medicines, transgenic production technology of aromatic species), new technology of wild animal domestication (the breeding and domestication technology of resident birds, the breeding domestication technology of herbivores, the breeding and domestication technology of aquatic animals, etc), the cultivation techniques of ecological leisure landscape (ecological forest cultivation technology, technology of creating artificial landscape, business technology of recreation and entertainment, etc.), and the use of bio-energy technology (the technology of power generation by using forestry residues, the technology of using photovoltaic materials in forest areas, bio-energy species in situ use of technology, etc.). 


\subsection{The choice of technological cluster}

If core technology is utilized effectively, it will inevitably induce an interrelated and complementary technological cluster. The technological cluster mentioned here refers to a technological system which is made up of interrelated plural technologies. Its goal is to support an industry commonly with economic developmental significance. Each individual technology has different and organic relation with the core technology in a technological cluster. These relations include: accessory technology, the technology of using downstream products directly, of packaging services, of raw materials supply, of resources for training, of control, of product design and testing, of the demonstration of marketing and so on. Take the manufacturing technology of super-activated carbon as an example. In a manufacturing technological cluster of super-activated carbon, there are the manufacturing technology of super-capacitor materials (using super-activated carbon directly), the manufacturing technology of super-capacitor (using downstream products directly), the technology of raw material produced by activated carbon (the supply of raw materials), the qualitative control technology of super-activated carbon (control product quality), the packaging and logistics technology of super-activated carbon and super-capacitor(marketing services), etc. All these technologies are indispensable technological elements in the development of super-activated carbon industry.

Each kind of industry needs supporting by adaptive technological cluster. The selection of the technological cluster should follow the following principles:

\subsubsection{Systemic principle}

The core technology and the accessory technologies are complementary or additive. For example, the technology of bio-enzyme degradation and the culture of flesh flies in industry of chitin new materials is a systemic technological integration at the aspect of resource utilization (Farmers can get chitin and protein powder of insects by culturing flesh flies, which reduces operational risks greatly). The technology of using bamboo--serum to produce paper and extracting vanillin from bamboo-lignin in paper-making industry is also a complementary technological system. The technological combination of shelter forest for farmland and Lin drugs (cultivation of economic forests and herbs) and the technological combination of cultivating fast-growing and high-yield forests and veneer(or wood fiber materials) packaging are as well as typical representatives of systemic technological cluster.

\subsubsection{Advanced principle}

The core technology and related technologies will be still able to maintain the normal technological support in the 5-10 years after being operated even though moderate technological innovation will be brought forward. For example, the technology of cultivating energy species and using new energy in bio-energy industry is not only one of the future developmental direction of energy industry, but also one of basic needs of building new rural areas (forest); the integration technology of large fiber (the technological system concentrates panels, paper, textiles and other industries to fibrosis) is a key to solve problems about environment, industrial transfer and resources supply in the future.

\subsubsection{The principle of leaving room}

If the selected technological cluster can adapt to diversified economy or the upgrading of industrial technology successfully in the industrial changes, it may have space to adapt to developmental elements' (industry resource, technology, economic mechanism, market) changes and make industrial operation stable. For example, the manufacture of downstream products should be left space by further development in process of producing forest products. The high-end activated 
carbon (such as high surface area activated carbon, etc.) should also be left space to install a new device in the process of manufacturing wood-based activated carbon. The space for tour routes and products utilizations should be left in the process of economic forest base construction.

\subsubsection{The principle of applicability}

The popularity and application of the selected technological cluster should adapt to technological staff (or entities) or the capacity scope of regional conditions. There are two sides: first, the technology is applied to technological staff (including foresters, businesses and other entities), and the second is that the technology is applied to natural economic conditions (sometimes also involving the social and cultural basis) of the region (the production area or market area). For example, satellite positioning technology is largely used for protecting(tracking) wild animals in the forest. At the present time it would not be applied to the technological staff or forest conditions. If the mode of operation of overall control of the company and peasant households respective processing (scattered parts manufacturing, quality uniform testing) is used in a original ecobamboo furniture manufacturing technology group, it perhaps not only suits for farmers, but also for bamboo areas.

\subsubsection{Controllable principle}

The core technology and accessory technologies should be able to carry out necessary adjustments at the aspect of the quantity and quality (including structure). That is because the technological factors also have their own metabolism and ever-changing objective law. For example, although the technology of raw materials supply and the plastic adhesive manufacture are both accessory technologies in the technological system of moderate (high) density fiberboard manufacture, the innovation of plastic adhesive manufacturing technology will inevitably cause changes of fiberboard manufacturing technology, and the innovation of raw materials supply technology also affects the developmental direction of fiber industrial technology (such as Japanese government cuts down giant fiberboard manufacturing cost through subsidizing the enterprises that reuse waste paper and waste fibers, which reduces a great deal of import fiberboard).

\subsection{Selection of new development direction for technological innovation}

Industrial design is always associated with the sustainable development of industry and the growth of the enterprise's core competence. Sustainable development of industry is the concept of economic theory, but it is often used to describe the regional and economic growth in developmental economics. Capital, labor, technology, equipment and other factors play an important role in the process of sustainable development. However, more attention is paid to the growths and changes of resources, technology, economic mechanisms and market when discussing sustainable development in industrial design. The industrial plan, organize, leadership, control and coordination can be realized by integrating and coordinating four elements (resources, technology, economic mechanisms and market). Innovation of industrial design strictly follows resources innovation, technological innovation, market development and innovation of economic mechanism. Core Competence has a same meaning with sustainable innovation capability and it is the sum of irreplaceable capability of corporate culture, exploiting markets, the growth mechanism of human resources and growth of intellectual property rights. Enterprise's core competence lies on continuous innovation of business (including technological innovation, innovation in the organizational system, market development, etc.).

In terms of economic mechanism, the use of creative achievements can improve the effectiveness of resource allocation (improve productivity, enhance total amount of resources or utilization efficiency of resource), and make market consumption persistent and rational. Technological innovation include the following: process innovation, new product development, 
the establishment of new production systems, new market development. First, process innovation-Economies of scale mainly focus on the cost of associated products which is also a weapon in price competition; because the most important outcome of process innovation is cost savings (resource saving or resource efficiency). Second, new product development--the new effect of main related products cause a market "structural revolution". Because new products (equivalent to the emergence of something new) always contain new culture and re-examine old culture, which will eventually become the new productivity or new references of the life. The signification of new product development leads to the industrial revolution directly. Because a new vital product is a breakthrough of technology (regardless of this new product in the early stages has not been authorized or has no market), and the new products basing on basic research have more deterrence economically (or militarily). Third, the new production system--mainly associates with the rationality of technology and the integrity of the production organization. Because a new production system basing on technological rationality is not only the basis for realizing productive forces smoothly, but also the basis for forming relation of production (economic mechanism). Forth, market development--mainly associated with the value. Because all the fruits of technological innovation, the outcomes in production process, and all intangible assets value in the business process must be realized through the market. Therefore, the market development for the fruits of technological innovation is not only the result of cultural and business activities, but also an operating platform for industries to be taken into account during the selection of technology.

However, technological innovation is still subject to the resource characteristics of industrial development, economic mechanisms and market development. Especially when strategic resources induced by new economic mechanisms and market are at the innovation stage, technological innovation must also adapt to this environment and promote technology innovation and resource development. In general, under circumstances of planned economy system, if scarce resources are demanded largely at the market, large and medium-sized enterprise will use technological innovation of resource efficiency and commercial production, and medium and small enterprises will also conduct a variety of assisted-technology innovation, promoting the development of industry-wide culture of innovation. Under circumstances of the market (competition) economy system, small and medium-sized enterprises usually rely on large and medium-sized enterprise, universities or research institutes to implement industrialization, because small and medium-sized enterprises can not gain profit after exhausting large sunk cost in such a big competition. In other words, large enterprises have inherent advantages on technological innovation in market economy system. However, when the large enterprise fill up a huge costs, they need to exert leverage effect of "economies of scale" to recover investment and go into a virtuous circle in a long period. So after completing the innovation, if technological innovation can be imitated by small and mediumsized enterprises, these enterprises will improve technology and produce products (or services) which have lower costs than large enterprises. This would be to accelerate the technological process from development to practice, and speed up the process of technological innovation (as well as the process of technological aging). To imitate the more technical the social stereotypes of the higher sunk costs to less social welfare, in this sense, the programmatic research and development basing on mutual assistance saves more resources than the freedom research and development which bases on market competition. Effective development and utilization of resources make society to be a balanceable system, and speed up the process of industrialization. Modern forestry as an example, comprehensive utilization of wood residues is a kind of innovation that needs to comprehensive plan and cooperation in government, product, study and research. Technological innovation of producing oleaginous wood is more dependent on the technological innovation of genetic modification and resource utilization, because the dynamic adjustment of economic benefits as well as the forest management which is long drives combined with drop shots extend the cycle, which the small and medium-sized enterprises can not deal with. Under these circumstances, planned economy system and the way of mutual cooperation is relatively favorable. 


\section{Summary}

No matter what core technology to be chosen in industry, it determines the industry whether has the space of technological development or not. Therefore, the choice of core technology for technique route design plays an important role. If core technology is utilized effectively, it will inevitably induce an interrelated and complementary technological cluster. Meanwhile in the forestry industry suitable technical clusters are needed in particular. In appropriate economic mechanism, the use of creative achievements can improve the effectiveness of resource allocation, and make market consumption persistent and rational. But technological innovation is still subject to the resource characteristics of industrial development, economic mechanisms and market development. In this sense, the programmatic research and development basing on mutual assistance saves more resources than the freedom research and development which bases on market competition. Effective development and utilization of resources make society to be a balanceable system, and speed up the process of industrialization.

\section{References}

1. Harrison, Bennett. Are industrial clusters losing their cluster? Technology Review [J]. 1994, 97(4).

2. Enright, M., Regional clusters and economic development: a research agenda [R]. paper presented to the conference on Regional Clusters and Business Networks 1993, Fredericton, New Brunswick, Canada ( revised version). 1995.

3. Jacobs, D., De Man, A. P., Clusters, Industrial Policy and Firm Strategy: A Menu Approach [J]. Technology Analysis \& Strategic Management. 1996- 04.

4. Deng Heping, Jiang Xin-xi. Geological New Material [M]. Hunan Science Press, 2006(206208)

5. Wang Tianying. Research on the Problems of the Presumption and Viability of Industrial Design and the Path of Choosing the Relevant Industries [J]. Economic Management, 2007(15) 